\title{
Hydrogenation effects on the lithium ion battery performance of $\mathrm{TiOF}_{2}$
}

Min $\mathrm{He}^{\mathrm{a}, \mathrm{b}}$, Zhihui Wang ${ }^{\mathrm{c}}$, Xiaodong Yan ${ }^{\mathrm{a}}$, Lihong Tian ${ }^{\mathrm{a}, \mathrm{d}}$, Gao Liu ${ }^{\mathrm{c} *}$ and Xiaobo Chen $^{\text {a* }}$

a. Department of Chemistry, University of Missouri-Kansas City, Kansas City, MO 64110, USA

b. Department of Applied Physical, College of Science, Wuhan University of Science \& Technology, Wuhan, Hubei 430065, China

c. Advanced Energy Technologies Department, Lawrence Berkeley National Laboratory, Berkeley, CA 94720,USA

d. Hubei Collaborative Innovation Center for Advanced Organochemical Materials, Hubei University, Wuhan, 430062, China

Corresponding authors.

E-mail address: Chenxiaobo@umkc.edu (X. Chen), Tel.: +1 510486 7202;

GLiu@lbl.gov (G. Liu), Tel.: +1 8162356420. 


\section{Abstract}

Hydrogenated titanium oxyfluorides $\left(\mathrm{TiOF}_{2}\right)$ nanoparticles were synthesized via one-pot hydrothermal method and subsequent hydrogenation treatment. As anode materials for lithium ion batteries, the hydrogenated $\mathrm{TiOF}_{2}$ showed a superior rate performance compared to the pristine $\mathrm{TiOF}_{2}$. A charge capacity of $118.4 \mathrm{~mA} \mathrm{~h} \mathrm{~g}^{-1}$ was achieved at the current density of $1053 \mathrm{~mA} \mathrm{~g}^{-1}$ upon 150 cycles, which was 4 times higher than that of the pristine $\mathrm{TiOF}_{2}$. The rate performance of the hydrogenated $\mathrm{TiOF}_{2}$ at different current density of 42, 210, 1053, 2106, 5265, 10530, 21060 and $52650 \mathrm{~mA} \mathrm{~g}^{-1}$ was $2.8,6.0,13.2,14.7,21.5,30.6,67.9$ and 483.3 times higher than those of the pristine $\mathrm{TiOF}_{2}$ electrode at the corresponding rates, respectively. The remarkable improvement of the electrochemical performance was likely related to the size breakdown in the (001) direction after hydrogenation, instead of oxygen vacancies induced better charge transfer properties.

Keywords: titanium oxyfluorides; hydrogenation; rate performance; lithium ion battery 


\section{Introduction}

Lithium ion batteries (LIBs) have become an essential part of various portable electronic devices such as mobile phones, laptops, digital cameras and e-bikes, and also been considered as a potential power source for electric vehicles (EVs) and hybrid electric vehicles (HEVs) due to their high specific energy, good cycle-ability and safety. The growing demands of LIBs have encouraged great efforts to develop a cheap and high-performance electrode material ${ }^{[1-2]}$. Recently, titanium oxide has attracted extensive attention as an anode material for LIBs due to its low cost, good stability, low toxicity and low volume expansion compared to other transition-metal oxides ${ }^{[3-4]}$. However, the low electrical conductivity $\left(\sim 10^{-13} \mathrm{~S} \mathrm{~cm}^{-1}\right)$ of $\mathrm{TiO}_{2}$ leads to a poor rate performance with a limited capacity, hindering its large-scale application ${ }^{[5-6]}$. Therefore, it is imperative to develop better anode materials for LIBs.

Some recent studies suggested that titanium oxyfluorides $\left(\mathrm{TiOF}_{2}\right)$ was a promising material for LIBs due to its higher theoretical specific capacity (1053 mAh $\left.\mathrm{g}^{-1}\right)$ and lower polarization than titanium oxides ${ }^{[7]} \cdot \mathrm{TiOF}_{2}$ is an air stable compound and can be easily obtained by hydrolysis of titanium tetrafluoride. $\mathrm{TiOF}_{2}$ possesses a cubic $\mathrm{ReO}_{3}$-type structure (space group $P m \overline{3} m$, perovskite structure) at room temperature based from the corner sharing $\mathrm{TiO}_{2} \mathrm{~F}_{4}$ octahedra with random distribution of $\mathrm{O}$ and $\mathrm{F}$ anions. Since the 12-fold O-coordinated site is empty and can accommodate other ions, thus, lithium ions could be inserted into the vacant octahedral sites ${ }^{[8,9]}$. It was proved that $\mathrm{TiOF}_{2}$ could be chemically or electrochemically lithiated using $n$-butyl lithium $\left(n\right.$-BuLi) ${ }^{[10-12]}$. Recent researches 
also showed that voltage window and synthesis method had an important influence on lithium storage capacity and mechanism. For example, Chowdari et al synthesized crystalline $\mathrm{TiOF}_{2}$ by using Ti metal powder and a 1:1 mixture of $\mathrm{HF}$ and $\mathrm{HNO}_{3}$. They found that the crystal structure of $\mathrm{TiOF}_{2}$ was destroyed during the first discharge reaction at voltage lower than $1 \mathrm{~V}$ in a $\mathrm{TiOF}_{2} / \mathrm{Li}$ half-cell system ${ }^{[12]}$. $\mathrm{TiOF}_{2}$ gave a capacity of $\sim 400 \mathrm{mAh} \mathrm{g}^{-1}$ without noticeable capacity fading in a voltage window of 0.005-3.0 V at a current density of $65 \mathrm{~mA} \mathrm{~g}^{-1}$ during 5-100 cycles ${ }^{[12]}$. Dambournet et al found that the titanium-based anion nanocomposites demonstrated dual lithium insertion and conversion mechanisms between 0.05 and $3 \mathrm{~V}^{[13]}$. Louvain et al synthesized $\mathrm{TiOF}_{2}$ by gas-solid fluorination of $\mathrm{TiO}_{2}$ anatase nanocrystals, and a capacity of $220 \mathrm{~mA} \mathrm{~h} \mathrm{~g}^{-1}$ was achieved at the current density of $2.63 \mathrm{~mA} \mathrm{~g}^{-1}$ at the voltage ranges of 1.2-3.8 $\mathrm{V}^{[14]}$. Yan's et al synthesized single-crystalline $\mathrm{TiOF}_{2}$ nanotubes via hydrothermal method, which showed a capacity of $391 \mathrm{mAh} \mathrm{g}^{-1}$ after 60 cycles at a current density of $400 \mathrm{~mA} \mathrm{~g}^{-1}$ within a charge-discharge range of 0.001-3 $\mathrm{V}^{[15]}$. Myung et al produced $\mathrm{TiOF}_{2}$ by a reaction of $\mathrm{TiO}_{2}$ and hydrofluoric acid. The synthesized $\mathrm{TiOF}_{2}$ delivered a charge capacity of $526 \mathrm{~mA} \mathrm{~h} \mathrm{~g} \mathrm{~g}^{-1}$ between 0.01 and $3 \mathrm{~V}$ versus $\mathrm{Li}{ }^{[16]}$. In spite of these progresses, the electrochemical performance of $\mathrm{TiOF}_{2}$ is still unsatisfying. Novel approaches are urgent to improve its cyclability and rate performance.

Very recently, hydrogenation has been attracting great interests in improving the electrochemical performance of anode materials ${ }^{[17-20]}$. Hydrogenation can change the arrangement of the atoms, form oxygen vacancies on the surface, and lead to 
surface-disordered structure ${ }^{[17,21-23]}$. The surface-disordered layer is beneficial to the charge transfer and lithium ion transport, resulting in a significant improvement in capacity, cyclability and rate performance ${ }^{[18,21-22]}$. Meanwhile, hydrogenation can also reduce the particle size and increase interface area, triggering the enhancement of the electrochemical reactions and reactivity ${ }^{[24-25]}$. Herein, we first reported $\mathrm{TiOF}_{2}$ treated by hydrogenation and its performance as anode material for LIBs. Compared with the pristine $\mathrm{TiOF}_{2}$, the hydrogenated $\mathrm{TiOF}_{2}$ with small particle size, surface-disordered structure and oxygen deficiency, was more favorable to quicken lithium ion transport and facilitate electronic transfer. Accordingly, remarkably enhanced lithium storage capacity, cyclability and rate performance were achieved.

\section{Experimental}

\subsection{Synthesis of hydrogenated $\mathrm{TiOF}_{2}$}

Hydrogenated $\mathrm{TiOF}_{2}$ was fabricated by a modified one-pot hydrothermal method [26-28] and subsequent hydrogenation treatment. Typically, Titanium butoxide (Ti $\left.\left(\mathrm{OC}_{4} \mathrm{H}_{9}\right)_{4}, 5 \mathrm{~mL}\right)$ and hydrofluoric acid solution $(0.6 \mathrm{~mL}, 48 \mathrm{wt} \%)$ were mixed in a Teflon-lined stainless steel autoclave and then kept at $200{ }^{\circ} \mathrm{C}$ for about $24 \mathrm{~h}$. After cooling down naturally, the obtained precipitates were centrifuged, washed with deionized water and ethanol several times, and finally dried at $80{ }^{\circ} \mathrm{C}$ overnight. For hydrogenation, the as-prepared products were calcinated at $250{ }^{\circ} \mathrm{C}$ for $3 \mathrm{~h}$ under flowing hydrogen. The sample was denoted as $\mathrm{H}-\mathrm{TiOF}_{2}$. For comparison, the hydrothermal products were also treated in a furnace at $250{ }^{\circ} \mathrm{C}$ for $3 \mathrm{~h}$ under flowing 
air, signed to be $\mathrm{TiOF}_{2}$.

\subsection{Materials characterization}

The X-ray diffraction patterns were checked using a Panalytical X'pert Pro diffractometer with high intensity $\mathrm{Cu} \quad \mathrm{K}_{\alpha}$ irradiation. Transmission electron microscopy (TEM) observations were carried out on a Philips CM 200 microscopy. Raman spectra was recorded using EZRaman-N Raman spectrometer equipped with a $300 \mathrm{~mW}$ diode laser (Enwave Optronics, Inc.) and the excitation wavelength was 785 nm. The FTIR spectra were collected using a Thermo-Nicolet iS10 FT-IR spectrometer with an attenuated total reflectance unit. The X-ray photoelectron spectra were measured on a PHI Versaprobe 5000 Scanning X-Ray Photoelectron Spectrometer (XPS). The samples were pasted on a conductive carbon tape. The electrical conductivity was measured with a Biologic potentiostat/electrochemical impedance spectroscopy instrument. The samples were pressed into small disks with diameter of $10.0 \mathrm{~mm}$, and thickness of $1.0 \mathrm{~mm}$. The pellets were sandwiched between two stainless steel disks for the conductivity measurements. The Mott-Schottky plots were collected with a scan rate of $10 \mathrm{mV} / \mathrm{s}$ in $0.5 \mathrm{M} \mathrm{H}_{2} \mathrm{SO}_{4}$ electrolyte at a frequency of $10 \mathrm{kHz}$ in a typical three-electrode system with $\mathrm{Pt}$ and $\mathrm{Ag} / \mathrm{AgCl}$ electrodes as the counter and reference electrodes, respectively ${ }^{[29,30]}$. The electrochemically active surface areas (ECSAs) of the catalysts were estimated from the double layer capacitance $\left(\mathrm{C}_{\mathrm{dl}}\right)$, as $\mathrm{C}_{\mathrm{dl}}$ was linearly proportional to the effective active surface area. The linear slope of the capacitive current against scan rate was used to represent the ECSA. The $\mathrm{C}_{\mathrm{dl}}$ was measured using a simple cyclic voltammetry method. The voltage 
window of cyclic voltammograms was $0.2-0.3 \mathrm{~V}$ vs $\mathrm{Ag} / \mathrm{AgCl}$. The scan rates were $10,20,40,60$, and $80 \mathrm{mV} \mathrm{s}^{-1}$ in $1.0 \mathrm{M} \mathrm{H}_{2} \mathrm{SO}_{4} \cdot \mathrm{C}_{\mathrm{dl}}$ was estimated by plotting the $\Delta \mathrm{j}$ $\left(\mathrm{j}_{\mathrm{a}}-\mathrm{j}_{\mathrm{c}}\right)$ at $0.25 \mathrm{~V}$ vs $\mathrm{Ag} / \mathrm{AgCl}$ against the scan rate, where the slope was twice as the $\mathrm{C}_{\mathrm{dl}}{ }^{[29]}$.

\subsection{Coin cell preparation and electrochemical measurement}

The standard 2325 coin cells were assembled in an argon-filled glove box where moisture and oxygen concentrations were strictly limited to below $1 \mathrm{ppm}$. The working electrode was fabricated by $82 \mathrm{wt} \%$ active materials, $8 \mathrm{wt} \%$ acetylene black and $10 \mathrm{wt} \%$ polyvinylidene fluoride (PVDF). The mixture was well dispersed in N-methylpyrrolidone (NMP) using a Polytron PT10-35 homogenizer at $2700 \mathrm{rpm}$ for $30 \mathrm{~min}$, and then the slurry was cast on a battery-grade copper foil using a doctor blade. After being dried overnight in an oven, the electrodes were cut into 12.7 mm-diameter discs and dried again before being assembled into cell. Lithium foil was used as the counter electrode, a Celgard 2400 membrane was used as the separator and $1 \mathrm{M}$ lithium hexafluorophosphate $\left(\mathrm{LiPF}_{6}\right)$ in ethylenecarbonate (EC): diethylcarbonate (DEC) (1:2 weight ratio) was used as the electrolyte.

Cells were tested between 1.0 and $3.0 \mathrm{~V}\left(\mathrm{vs} . \mathrm{Li} / \mathrm{Li}^{+}\right.$) using a Maccor battery cyler at $30{ }^{\circ} \mathrm{C}$. The first discharge and charge cycle were tested at a current density of 42 $\mathrm{mA} \mathrm{g}^{-1}$ (where $\mathrm{C}$ was calculated from a specific capacity value of $1053 \mathrm{mAh} \mathrm{g}^{-1}$ ), and the second one was at a current density of $210 \mathrm{~mA} \mathrm{~g}^{-1}$. Then the cell were cycled at a current density of $1053 \mathrm{~mA} \mathrm{~g}^{-1}$. For the rate performance test, the charge and discharge rates were changed symmetrically. 


\section{Results and discussions}

The phase and crystallinity of pristine and hydrogenated $\mathrm{TiOF}_{2}$ were tested by power XRD. As shown in Fig. 1a, the strong diffraction peaks indicated high crystallinity and could be identified to be cubic $\mathrm{TiOF}_{2}$ (JCPDS No. 77-0132, Pm-3m, $\mathrm{a}=\mathrm{b}=\mathrm{c}=3.780 \AA$ ). No impurity was found in both pristine and hydrogenated $\mathrm{TiOF}_{2}$. The average crystalline size of the pristine $\mathrm{TiOF}_{2}$ and hydrogenated $\mathrm{TiOF}_{2}$ were evaluated using the Scherrer formula: $\tau=k \lambda /(\beta \cos \theta)$, where $\tau, k, \lambda, \beta$ and $\theta$ are the mean size of the ordered (crystalline) domains, the shape factor with a typical value of 0.9 , the $\mathrm{X}$-ray wavelength $(0.15418 \mathrm{~nm}$ for $\mathrm{Cu}-\mathrm{K} \alpha)$, the line broadening full width at half maximum (FWHM) of the diffraction peak height in radians, and the Bragg diffraction angle, respectively ${ }^{[31]}$. The crystalline size of the original $\mathrm{TiOF}_{2}$ is 39.4, 34.9, 29.6, 28.6 and $23.6 \mathrm{~nm}$ along (100), (110), (200), (210) and (211) direction, respectively, while the size of crystalline phase of $\mathrm{H}-\mathrm{TiOF}_{2}$ change into 35.9, 33.6, 31.2, 31.9 and $27.9 \mathrm{~nm}$ along the corresponding directions. This suggested that the size of crystalline phase of hydrogenated $\mathrm{TiOF}_{2}$ shrunk $8.88 \%(3.5 \mathrm{~nm})$ and $3.72 \%$ (1.3 nm) along (100) and (110). However, a slightly increase in (200), (210) and (211) directions was observed.

In order to further reveal the structural evolution and surface functional groups in the $\mathrm{TiOF}_{2}$ nanocrystals during hydrogenation process, Raman spectra of the original $\mathrm{TiOF}_{2}$ and hydrogenated $\mathrm{TiOF}_{2}$ were collected. For $\mathrm{TiOF}_{2}$, there were five active bands with wavenumber at $248\left(\mathrm{~B}_{1 \mathrm{~g}}\right), 394\left(\mathrm{~B}_{1 \mathrm{~g}}\right), 530,634\left(\mathrm{E}_{\mathrm{g}}\right), 760 \mathrm{~cm}^{-1}$, respectively (Fig. 1b), which corresponded to the typical Raman spectra of $\mathrm{TiOF}_{2}$ 
except a slight shift $\left(\sim 14 \mathrm{~cm}^{-1}\right)$ toward higher wavenumber of some peaks ${ }^{[22,28]}$. Interestingly, two frequency bands at 248 and $760 \mathrm{~cm}^{-1}$ were observed, which were also detected in another study ${ }^{[32]}$. After hydrogenation, these active bands disappeared, which indicated oxygen deficiency and the appearance of some disorder by the hydrogen treatment ${ }^{[17,21,33]}$.

Morphologies and microstructure of original $\mathrm{TiOF}_{2}$ and hydrogenated $\mathrm{TiOF}_{2}$ were checked by TEM characterization. Fig. 2a-2c displayed a typical TEM image of $\mathrm{TiOF}_{2}$ nanocubes with a size of 300-500 nm. HRTEM analyses (Fig. 2c) showed the distinct lattice fringes, indicating good crystallinity. However, after hydrogenation, the morphology of $\mathrm{TiOF}_{2}$ were greatly changed from cube to nanosheets with smaller thickness (Fig. 2d and 2e). These $\mathrm{TiOF}_{2}$ nanosheets were similar in morphology to the $\mathrm{TiO}_{2}$ nanosheets formed in the preparation of the large $\mathrm{TiOF}_{2}$ cubes ${ }^{[26-28]}$. HRTEM image in Fig. 2f showed some amouphous phase in the hydrogenated $\mathrm{TiOF}_{2}$, these amouphous phase is favorable to transport of ion. Meanwhile, it showed layered structures of smaller nanosheets. The layered structure was very similar to the $\mathrm{TiOF}_{2}$ cubes formed due to the (001) stacking of the $\mathrm{TiO}_{2}$ nanosheets during the hydrothermal synthesis ${ }^{[28]}$. Thus, it seemed that during the hydrogenation reaction, large $\mathrm{TiOF}_{2}$ cubes reconstructed into smaller $\mathrm{TiOF}_{2}$ nanosheets which were stacked with (001)-faceted $\mathrm{TiOF}_{2}$ nanosheets. (001)-faceted $\mathrm{TiO}_{2}$ has shown better lithium ion battery performance than spherical $\mathrm{TiO}_{2}$ nanoparticles due to preferential charge transfer across the (001) facet ${ }^{[34]}$. Thus, it is expected that hydrogenated $\mathrm{TiOF}_{2}$ will have similar enhancement. 
Fig. $3 \mathrm{a}$ and $3 \mathrm{~b}$ demonstrated the charge-discharge curves of the original $\mathrm{TiOF}_{2}$ and hydrogenated $\mathrm{TiOF}_{2}$ at different cycles. It can be seen that there was a substantial difference between the first cycle and subsequent cycles. The original $\mathrm{TiOF}_{2}$ electrode displayed two distinct voltage plateaus at about 1.8 and $2.6 \mathrm{~V}$ in the initial discharge process, corresponding to a chemical lithiation process ${ }^{[13,16,35]}$. After the second cycle, the charge/discharge voltage plateaus located at $1.9 / 1.7-1.8 \mathrm{~V}$. The Li ion intercalation/deintercalation reaction in $\mathrm{TiOF}_{2}-\mathrm{Li}$ system was similar to that of $\mathrm{TiO}_{2}-\mathrm{Li}$ system, which followed a reversible reaction: $\mathrm{TiO}_{2}+\mathrm{xLi}+\mathrm{xe} \mathrm{e}^{-} \rightarrow \mathrm{Li}_{\mathrm{x}} \mathrm{TiO}_{2}$, indicating the good lithium insertion/desertion and the good reversibility of the Li-TiOF 2 system ${ }^{[7,12]}$. Interestingly, the hydrogenated $\mathrm{TiOF}_{2}$ electrode displayed an additional lithium insertion plateau at about $1.2 \mathrm{~V}$ (Fig. 3b), which meant lithium ions might insert into cubic/rhombohedral phase boundary and induced the transition between cubic and rhombohedral for $\mathrm{ReO}_{3}$ phase due to the decrease of particle size and the increase of amorphous phase after hydrogenation ${ }^{[13,21,35]}$. Meanwhile, the potential difference of the hydrogenated $\mathrm{TiOF}_{2}$ electrode was smaller than that of the original $\mathrm{TiOF}_{2}$ electrode between the charge and discharge cycles, which implied smaller charge transfer resistance and faster lithium ion transport after hydrogenation treatment. Recent researches indicated that interface lithium storage might occur according to the slope of the discharge curves, which enhanced capacity and rate performance $^{[21,35]}$.

Indeed, it can be observed from Fig. $3 \mathrm{a}-\mathrm{d}$ that the charge-discharge capacity, cycle stability and columbic efficiency of hydrogenated $\mathrm{TiOF}_{2}$ showed obvious 
improvement compared with those of the original $\mathrm{TiOF}_{2}$. In detail, the original $\mathrm{TiOF}_{2}$ delivered the initial charge and discharge capacities of 101.8 and $145.3 \mathrm{~mA} \mathrm{~h} \mathrm{~g}^{-1}$ at a current density of $42 \mathrm{~mA} \mathrm{~g}^{-1}$, respectively, corresponding to an initial coulombic efficiency of 53.0\%. The initial capacity loss might result from irreversible lithium insertion due to possible phase transition. The charge capacity and coulombic efficiency for the original $\mathrm{TiOF}_{2}$ maintained $39.1 \mathrm{~mA} \mathrm{~h} \mathrm{~g}^{-1}$ and $56.7 \%$ at the second cycle at a current density of $210 \mathrm{~mA} \mathrm{~g}^{-1}$, and around $22 \mathrm{~mA} \mathrm{~h} \mathrm{~g}^{-1}$ and above $75 \%$ after the third cycle at a current density of $1053 \mathrm{~mA} \mathrm{~g}^{-1}$, then the capacity kept slight increase and reached $29.8 \mathrm{~mA} \mathrm{~h} \mathrm{~g}^{-1}$ after 150 cycles from Fig. 3c. The specific capacity reduced with increase of current density that indicated the kinetics was limited by slow electronic and ion diffusion. Compared to the large theoretical capacity of $\mathrm{TiOF}_{2}$, the small capacity obtained here could be related to the poor usage of the actual $\mathrm{TiOF}_{2}$ volume during charge/discharge process due to the limited diffusion length within certain charge/discharge time, as the size of the $\mathrm{TiOF}_{2}$ crystals was on the order of a few hundreds of nanometers and the charge diffusion coefficients in oxides were very small. However, after hydrogenation, the first charge and discharge capacity increased to 254.8 and $338.1 \mathrm{~mA} \mathrm{~h} \mathrm{~g}^{-1}$ at a current density of $42 \mathrm{~mA} \mathrm{~g}^{-1}$, respectively, resulting in an initial coulombic efficiency of $75.4 \%$, which was $42 \%$ higher than that of the original $\mathrm{TiOF}_{2}$. During the second cycle, the charge-discharge capacity of the hydrogenated $\mathrm{TiOF}_{2}(170.5$ and $196.9 \mathrm{~mA} \mathrm{~h} \mathrm{~g}$ - $)$ were much higher than that of the original $\mathrm{TiOF}_{2}\left(39.1\right.$ and $\left.69.1 \mathrm{~mA} \mathrm{~h} \mathrm{~g}^{-1}\right)$ at a current density of $210 \mathrm{~mA} \mathrm{~g}^{-1}$. From the third cycle to 150 th cycle at a current density of 1053 
$\mathrm{mA} \mathrm{g}^{-1}$, the capacity of the hydrogenated $\mathrm{TiOF}_{2}$ electrode remained relatively stable in the range from 110.7 to $124.9 \mathrm{~mA} \mathrm{~h} \mathrm{~g}^{-1}$, and the specific charge capacity was maintained at $118.4 \mathrm{~mA} \mathrm{~h} \mathrm{~g}^{-1}$ after 150 cycles, which was 4 times higher than that of the original $\mathrm{TiOF}_{2}$ from Fig. 3c. As shown in Fig. 3d, the coulombic efficiency of the hydrogenated $\mathrm{TiOF}_{2}$ samples reached above $90 \%$ after the third cycle, and stabilized above $98 \%$ after the fifth cycle. By contrast, the original $\mathrm{TiOF}_{2}$ product only showed the coulombic efficiency of $90 \%$ after the tenth cycle, and slowly increased to above 98\% after 30 cycles. Apparently, the electrochemical performance of the hydrogenated $\mathrm{TiOF}_{2}$ was superior to that of the original $\mathrm{TiOF}_{2}$ and much better than the previous reported the $\mathrm{TiOF}_{2}$ electrodes ${ }^{[12,14-16]}$.

The improvement of the cycle performance and coulombic efficiency for the hydrogenated $\mathrm{TiOF}_{2}$ electrode can be attributed to the following reasons: on the one hand, the hydrogenation process decreased the grain size, increased the disorder layer and interface area, which lowered the lithium ion transport resistance, and allowed better adsorption of electrolyte and easier lithium ion insertion-desertion within interface transfer compared to the crystalline $\mathrm{TiOF}_{2}$, resulting in higher electrochemical activity and more interface lithium storage compared with the original $\mathrm{TiOF}_{2}$, thus improving lithium storage capacity ${ }^{[14,18]}$; on the other hand, the hydrogenation treatment could help to quicken transfer of electron and transport of lithium ion due to the possible formation of oxygen vacancy from Raman spectrum ${ }^{[21,}$ 22].

In order to further evaluate influence of hydrogenation on lithium storage, the 
rate capability of the original $\mathrm{TiOF}_{2}$ and hydrogenated $\mathrm{TiOF}_{2}$ at different current density were examined (Fig. 4). The hydrogenated $\mathrm{TiOF}_{2}$ electrode exhibited the average specific charge capacity of 293.9, 208.3, 163.2, 143.9, 115.4, 93.7, 70.6 and $40.6 \mathrm{~mA} \mathrm{~h} \mathrm{~g}^{-1}$ at the current density of 42, 210, 1053, 2106, 5265, 10530, 21060 and $52650 \mathrm{~mA} \mathrm{~g}^{-1}$, respectively. The specific charge capacity bounced back to $165.2 \mathrm{~mA} \mathrm{~h}$ $\mathrm{g}^{-1}$ when the current density returned to $1050 \mathrm{~mA} \mathrm{~g}^{-1}$. By contrast, the original $\mathrm{TiOF}_{2}$ electrode only showed a negligible specific charge capacity $\left(<10 \mathrm{~mA} \mathrm{~h} \mathrm{~g}^{-1}\right)$ when the current density exceeded $1053 \mathrm{~mA} \mathrm{~g}^{-1}$. The enhancement of the specific charge capacity at different current density was displayed in Fig. 4 (b). The rate performance of the hydrogenated $\mathrm{TiOF}_{2}$ at different current densities of 42, 210, 1053, 2106, 5263, 10530, 21060 and $52650 \mathrm{~mA} \mathrm{~g}^{-1}$ was $2.8,6.0,13.2,14.7,21.5,30.6,67.9$ and 483.3 times higher than those of the original $\mathrm{TiOF}_{2}$ electrode at the corresponding rate, respectively. The remarkably improving rate performance is likely related to the preferential charge transfer across the (001) facet, the unique amorphous or disordered

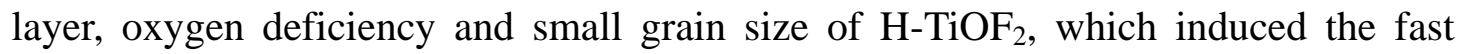
transport of lithium ion, the convenient accessibility of electrolyte and the easy transfer of electron ${ }^{[18,21-22]}$.

In order to improve our understanding of why $\mathrm{H}-\mathrm{TiOF}_{2}$ showed a better performance than the pristine $\mathrm{TiOF}_{2}$ crystals, we performed a series of analysis. It is suggested by the Raman measurements and TEM analysis that $\mathrm{H}-\mathrm{TiOF}_{2}$ might have oxygen deficiency and the appearance of some disorder by hydrogen treatment. Fig. 5A shows the global survey spectra of $\mathrm{TiOF}_{2}$ and $\mathrm{H}-\mathrm{TiOF}_{2}$ with the major difference 
in the F 1s signal. All the spectra were calibrated to the carbon signal from the carbon tape at $284.6 \mathrm{eV}$. Fig. 5B shows the core-level Ti 2p XPS spectra, which suggested $\mathrm{Ti}^{4+}$ ions for both samples with the $\mathrm{Ti} 2 \mathrm{p} 3 / 2$ peak at $458.8 \mathrm{eV}$ and the Ti $2 \mathrm{p} 1 / 2$ peak at 464.6 eV. Fig. 5C shows the core-level O 1s XPS spectra. Both $\mathrm{TiOF}_{2}$ and $\mathrm{H}_{-} \mathrm{TiOF}_{2}$ had a major $\mathrm{O} 1 \mathrm{~s}$ peak at $530.0 \mathrm{eV}$ from the $\mathrm{O}^{2-}$ ions in the lattice. $\mathrm{TiOF}_{2}$ had two shoulder peaks around $531.9 \mathrm{eV}$ and near $533.3 \mathrm{eV}$, which matched well with the oxygen in the adsorbed water and hydroxyl groups on the surface. While $\mathrm{H}_{-} \mathrm{TiOF}_{2}$ only had a small shoulder peak around $531.9 \mathrm{eV}$. This peak was likely from oxygen vacancy instead of hydroxyl groups as suggested later from FTIR spectrum. Fig. 5D shows the core-level F 1s XPS spectra. $\mathrm{TiOF}_{2}$ had a peak at $684.7 \mathrm{eV}$ while this peak decreased for $\mathrm{H}-\mathrm{TiOF}_{2}$, indicating that the hydrogenation treatment likely removed some of the surface fluorine ions.

Fig. 6A shows the FTIR spectra of $\mathrm{TiOF}_{2}$ and $\mathrm{H}-\mathrm{TiOF}_{2}$. For the $\mathrm{TiOF}_{2}$, the broad band centered at $3460 \mathrm{~cm}^{-1}$ and the peak at $1645 \mathrm{~cm}^{-1}$ were due to $\mathrm{O}-\mathrm{H}$ stretching and bending of strongly adsorbed $\mathrm{H}_{2} \mathrm{O}$, respectively. The peaks at $986 \mathrm{~cm}^{-1}$ and $903 \mathrm{~cm}^{-1}$ was due to the Ti-F and Ti-O vibrations in the $\mathrm{TiOF}_{2}$, respectively ${ }^{[26-28]}$. These fine IR characteristics were almost disappeared for $\mathrm{H}_{-} \mathrm{TiOF}_{2}$. Instead an increased featureless broad band whose intensity increased as the wavenumber decreased was observed across the entire IR region for $\mathrm{H}-\mathrm{TiOF}_{2}$, indicating the existence of oxygen vacancy defects with various energies. Fig. $6 \mathrm{~B}$ shows the $\mathrm{I}-\mathrm{V}$ curves of $\mathrm{TiOF}_{2}$ and $\mathrm{H}-\mathrm{TiOF}_{2}$. The resistivity of $\mathrm{TiOF}_{2}\left(1.91 \times 10^{12} \Omega / \mathrm{m}\right)$ was smaller than that of $\mathrm{H}-\mathrm{TiOF}_{2}(2.74 \times$ $\left.10^{12} \Omega / \mathrm{m}\right)$. Fig. $6 \mathrm{C}$ shows the Mott-Schottky plots of $\mathrm{TiOF}_{2}$ and $\mathrm{H}_{-\mathrm{TiOF}}$. As both 
showed positive slopes, they were n-type semiconductors with electrons as majority carriers. The carrier density $\mathrm{N}_{\mathrm{D}}$ were calculated from the slope with $\mathrm{N}_{\mathrm{d}}=$ $\left(2 / \mathrm{e} \varepsilon \varepsilon_{0}\right) /\left[\mathrm{d}\left(1 / \mathrm{C}^{2}\right) / \mathrm{dV}\right]$, where $\mathrm{C}$ is the interfacial capacitance, is $\mathrm{V}$ is the applied voltage, e is the electronic charge, and $\varepsilon$ is the dielectric constant ${ }^{[36]}$. The $\mathrm{H}_{-} \mathrm{TiOF}_{2}$ had a lower carrier density than $\mathrm{TiOF}_{2}$, as the carrier density $\mathrm{N}_{\mathrm{D}}$ is inversely proportional to the slope. Fig. $6 \mathrm{D}$ shows the ECSAs of $\mathrm{TiOF}_{2}$ and $\mathrm{H}-\mathrm{TiOF}_{2}$. The electrochemically active surface areas (ECSAs) of the catalysts were estimated from the double layer capacitance $\left(\mathrm{C}_{\mathrm{dl}}\right)$, as $\mathrm{C}_{\mathrm{dl}}$ was linearly proportional to the effective active surface area ${ }^{[29]}$. The linear slope of the capacitive current against scan rate was used to represent the ECSA. $\mathrm{C}_{\mathrm{dl}}$ was estimated by plotting the $\Delta \mathrm{j}\left(\mathrm{j}_{\mathrm{a}}-\mathrm{j}_{\mathrm{c}}\right)$ at $0.25 \mathrm{~V}$ vs $\mathrm{Ag} / \mathrm{AgCl}$ against the scan rate, where the slope was twice as the $\mathrm{C}_{\mathrm{dl}}{ }^{[29]}$. $\mathrm{H}-\mathrm{TiOF}_{2}$ had a 12-fold increase in ECSA compared with $\mathrm{TiOF}_{2}$. Based on the above results, the enhanced LIB performance of the $\mathrm{H}_{-}-\mathrm{TiOF}_{2}$ over $\mathrm{TiOF}_{2}$ was most likely due to the enhancement of the ECSA as a result of the size shrinkage after hydrogenation, instead of the changes of electrical conductivity or carrier density. This is different from previous studies that hydrogenation induced the improvement of electrical conductivity and carrier density of $\mathrm{TiO}_{2}$ nanomaterials through the creation of oxygen vacancies to improve their LIB performance ${ }^{[18,21]}$. The difference might be related to the existence of the fluorine in the $\mathrm{TiOF}_{2}$. Nevertheless, hydrogenation did improve the LIB performance of $\mathrm{TiOF}_{2}$, but through the break-down of the particle size of $\mathrm{TiOF}_{2}$, thus providing additional channel in improving the performance of LIB materials. 


\section{Conclusions}

In conclusion, we have successfully synthesized hydrogenated titanium oxyfluoride by one-pot hydrothermal treatment combined with a simple hydrogenation process. As anode material for LIBs, the hydrogenated $\mathrm{TiOF}_{2}$ electrode exhibited much higher lithium storage capacity and rate performance than the original $\mathrm{TiOF}_{2}$ electrode. The high electrochemical performance made such hydrogenated titanium oxyfluoride an attractive anode material for LIBs.

\section{Acknowledgments}

X. C. thanks the support from College of Arts and Sciences, University of Missouri Kansas City and the University of Missouri Research Board. G. L. thanks the fund by the Assistant Secretary for Energy Efficiency, Office of Vehicle Technologies of the United State Department of Energy under Contract No. DE-AC03-76SF00098. M. H. thanks the fund from China Scholarship Council for its financial support. L. T. thanks China Scholarship Council for it financial support.

\section{Reference}

[1] J.-M. Tarascon, M. Armand, Nature, Issues and challenges facing rechargeable lithium batteries, Nature 414 (2001) 359-367.

[2] A. S. Aricò, P. Bruce, B. Scrosati, J. -M. Tarascon, W. van Schalkwijk, Nanostructured materials for advanced energy conversion and storage devices, Nat. Mater. 4 (2005) 366-377.

[3] X. Chen, C. Li, M. Grätzel, R. Kostecki, S. S. Mao, Nanomaterials for renewable energy production and storage, Chem. Soc. Rev. 41 (2012) 7909-7937. 
[4] Z. Yang, D. Choi, S. Kerisit, K. M. Rosso, D. Wang, J. Zhang, G. Graff, J. Liu, Nanostructures and lithium electrochemical reactivity of lithium titanites and titanium oxides: A review, J. Power Sources 192 (2009) 588-598.

[5] R. J. Cava, D. W. Murphy, S. Zahurak, A. Santoro, R. S. Roth, The crystal structures of the lithium-inserted metal oxides $\mathrm{Li}_{0.5} \mathrm{TiO}_{2}$ anatase, $\mathrm{LiTi}_{2} \mathrm{O}_{4}$ spinel, and $\mathrm{Li}_{2} \mathrm{Ti}_{2} \mathrm{O}_{4}$, J. Solid State Chem. 53 (1984) 64-75.

[6] H. Lindström, S. Södergren, A. Solbrand, H. Rensmo, J. Hjelm, A. Hagfeldt, S. -E. Lindquist, $\mathrm{Li}^{+}$Ion Insertion in $\mathrm{TiO}_{2}$ (Anatase). 2. Voltammetry on Nanoporous Films, J. Phys. Chem. B 101 (1997) 7717-7722.

[7] L. Chen, L. Shen, P. Nie, X. Zhang, H. Li, Facile hydrothermal synthesis of single crystalline $\mathrm{TiOF}_{2}$ nanocubes and their phase transitions to $\mathrm{TiO}_{2}$ hollow nanocages as anode materials for lithium-ion battery, Electrochem. Acta 62 (2012) 408-415.

[8] K. Vorres, J. Donohue, The structure of titanium oxydifluoride, Acta Cryst. 8 (1955) 25-26.

[9] S. Shian, K. H. Sandhage, Hexagonal and cubic TiOF 2 , J. Appl. Crystallogr. 43 (2010) $757-761$.

[10] D. W. Murphy, M. Greenblatt, R. J. Cava, S. M. Zahurak, Topotactic lithium reactions with $\mathrm{ReO}_{3}$ related shear structures, Solid State Ionics, 5 (1981) 327-329.

[11] R. J. Cava, A. Santoro, D. W. Murphy, S. Zahurak, R. S. Roth, The structures of lithium-inserted metal oxides: $\mathrm{LiReO}_{3}$ and $\mathrm{Li}_{2} \mathrm{ReO}_{3}$, J. Solid State Chem. 42 (1982) 251-262.

[12] M. V. Reddy, S. Madhavi, G. V. Subba Rao, B. V. R. Chowdari, Metal oxyfluorides $\mathrm{TiOF}_{2}$ and $\mathrm{NbO}_{2} \mathrm{~F}$ as anodes for Li-ion batteries, J. Power Sources 162 (2006) 1312-1321.

[13] D. Dambournet, K. W. Chapman, P. J. Chupas, R. E. Gerald, N. Penin, C. Labrugere, A. 
Demourgues, A. Tressaud, K. Amine, Dual Lithium Insertion and Conversion Mechanisms in a Titanium-Based Mixed-Anion Nanocomposite, J. Am. Chem. Soc. 133 (2011) $13240-13243$.

[14] N. Louvain, Z. Karkar, M. El-Ghozzi, P. Bonnet, K. Gu'erin, P. Willmann, Fluorination of anatase $\mathrm{TiO}_{2}$ towards titanium oxyfluoride $\mathrm{TiOF}_{2}$ : a novel synthesis approach and proof of the Li-insertion mechanism, J. Mater. Chem. A 2 (2014) 15308-15315.

[15] Y. Zeng, W. Zhang, C. Xu, N. Xiao, Y. Huang, D. Y. W. Yu, H. H. Hng, Q. Yan, One-Step Solvothermal Synthesis of Single-Crystalline $\mathrm{TiOF}_{2}$ Nanotubes with High Lithium-Ion Battery Performance, Chem. Eur. J. 18 (2012) 4026-4030.

[16] S. -T. Myung, M. Kikuchi, C. S. Yoon, H. Yashiro, Y. -K. Sun, A new synthetic method of titanium oxyfluoride and its application as an anode material for rechargeable lithium batteries, J. Power Sources 288 (2015) 376-383.

[17] X. Chen, L. Liu, P. Y. Yu, S. S. Mao, Increasing Solar Absorption for Photocatalysis with Black Hydrogenated Titanium Dioxide Nanocrystals, Science, 331 (2011) 746-750.

[18] T. Xia, W. Zhang, W. Lia, N. A. Oylera, G. Liu, X. Chen, Hydrogenated surface disorder enhances lithium ion battery performance, Nano Energy, 2 (2013) 826-835.

[19] J. Lu, Y. Dai, H. Jin, B. Huang, Effective increasing of optical absorption and energy conversion efficiency of anatase $\mathrm{TiO}_{2}$ nanocrystals by hydrogenation, Phys. Chem. Chem. Phys. 13 (2011) 18063-18068.

[20] G. Wang, H. Wang, Y. Ling, Y. Tang, X. Yang, R. C. Fitzmorris, C. Wang, J. Z. Zhang, Y. Li, Hydrogen-Treated $\mathrm{TiO}_{2}$ Nanowire Arrays for Photoelectrochemical Water Splitting, Nano Lett. 11 (2011) 3026-3033. 
[21] J. -Y. Shin, J. H. Joo, D. Samuelis, J. Maier, Oxygen-Deficient $\mathrm{TiO}_{2-\delta}$ Nanoparticles via Hydrogen Reduction for High Rate Capability Lithium Batteries, Chem. Mater. 24 (2012) $543-551$.

[22] J. Qiu, S. Li, E. Gray, H. Liu, Q. -F. Gu, C. Sun, C. Lai, H. Zhao, S. Zhang, Hydrogenation Synthesis of Blue $\mathrm{TiO}_{2}$ for High-Performance Lithium-Ion Batteries, J. Phys. Chem. C 118 (2014) 8824-8830.

[23] T. Xia, X. Chen, Revealing the structural properties of hydrogenated black $\mathrm{TiO}_{2}$ nanocrystals, J. Mater. Chem. A 1 (2013) 2983-2989.

[24] M. Wagemaker, W. J. H. Borghols, F. M. Mulder, Large Impact of Particle Size on Insertion Reactions. A Case for Anatase $\mathrm{Li}_{x} \mathrm{TiO}_{2}$, J. Am. Chem. Soc. 129 (2007) 4323-4327.

[25] L. Kavan, M. Kalbac, M. Zukalova, I. Exnar, V. Lorenzen, R. Nesper, M. Graetzel, Lithium Storage in Nanostructured $\mathrm{TiO}_{2}$ Made by Hydrothermal Growth, Chem. Mater. 16 (2004) $477-485$.

[26] Y. Zhang, T. Xia, M. Shang, P. Wallenmeyer, D. Katelyn, A. Peterson, J. Murowchick, L. Dong, X. Chen, Structural evolution from $\mathrm{TiO}_{2}$ nanoparticles to nanosheets and their photocatalytic performance in hydrogen generation and environmental pollution removal, RSC Adv. 4 (2014) 16146-16152.

[27] Y. Zhang; Q. Zhang; T. Xia; D. Zhu; Y. Chen, X. Chen, The Influence of Reaction Temperature on the Formation and Photocatalytic Hydrogen Generation of (001) Faceted $\mathrm{TiO}_{2}$ Nanosheets, ChemNanoMat. 1 (2015), 270-275.

[28] Y. Zhang, M. Shang, Y. Mi, T. Xia, P. Wallenmeyer, J. Murowchick, L. Dong, Q. Zhang, X. Chen Influence of the amount of $\mathrm{HF}$ on the formation of $(001)$ faceted $\mathrm{TiO}_{2}$ nanosheets and 
their photocatalytic hydrogen generation performance, ChemPlusChem 79 (2014), $1159-1166$

[29] X. Yan; L. Tian; X. Chen Crystalline/amorphous Ni/NiO core/shell nanosheets as highly active electrocatalysts for hydrogen evolution reaction, J. Power Sources, 300 (2015), $336-343$.

[30] X. Yan, L. Tian, M. He, X. Chen Three-Dimensional Crystalline/Amorphous $\mathrm{Co} / \mathrm{Co}_{3} \mathrm{O}_{4}$ Core/Shell Nanosheets as Efficient Electrocatalysts for the Hydrogen Evolution Reaction, Nano Lett. 15 (2015), 6015-6021.

[31] R. Jenkins, R. L. Snyder, Introduction to X-ray Powder Diffrac- tometry, John Wiley \& Sons Inc., New York, 1996.

[32] C. Z. Wen, Q. H. Hu, Y. N. Guo, X. Q. Gong, S. Z. Qiao, H. G. Yang, From Titanium Oxydifluoride $\left(\mathrm{TiOF}_{2}\right)$ to Titania $\left(\mathrm{TiO}_{2}\right)$ : Phase Transition and Non-metal Doping with Enhanced Photocatalytic Hydrogen $\left(\mathrm{H}_{2}\right)$ Evolution Properties, Chem. Commun. 47 (2011) $6138-6140$.

[33] G. Liu, H. G. Yang, X. Wang, L. Cheng, H. Lu, L. Wang, G. Q. (Max) Lu, H. -M. Cheng, Enhanced Photoactivity of Oxygen-Deficient Anatase TiO2 Sheets with Dominant $\{001\}$ Facets, J. Phys. Chem. C 113 (2009) 21784-21788.

[34] Z. Wang, Y. Zhang, T. Xia, J. Murowchick, G. Liu, X. Chen, Lithium-ion battery performance of (001) faceted $\mathrm{TiO} 2$ nanosheets vs. spherical TiO2 nanoparticles, Energy Technology 2 (2014) 376-382.

[35] J. -Y. Shin, D. Samuelis, J. Maier, Sustained Lithium-Storage Performance of Hierarchical, Nanoporous Anatase $\mathrm{TiO}_{2}$ at High Rates: Emphasis on Interfacial Storage Phenomena, Adv. 
Funct. Mater. 21 (2011) 3464-3472.

[36] G. Wang, Y. Ling, D. A. Wheeler, K. E. N. George, K. Horsley, C. Heske, J. Z. Zhang, Y. Li, Facile synthesis of highly photoactive $\alpha-\mathrm{Fe}_{2} \mathrm{O}_{3}$-based films for water oxidation. Nano Letters 11 (2011), 3503-3509. 


\section{Figure captions}

Fig. 1. XRD patterns (a) and Raman spectra (b) of as-synthesized $\mathrm{TiOF}_{2}$ and $\mathrm{H}-\mathrm{TiOF}_{2}$

Fig. 2. TEM and HRTEM images of the original $\mathrm{TiOF}_{2}(\mathrm{a}-\mathrm{c})$ and hydrogenated $\mathrm{TiOF}_{2}$ (d-f)

Fig. 3. Galvanostatic charge/discharge profiles at the first cycle at a current density of $42 \mathrm{~mA} \mathrm{~g}^{-1}$, the second cycle at a current density of $210 \mathrm{~mA} \mathrm{~g}^{-1}$, and then other cycles at a current density of $1053 \mathrm{~mA} \mathrm{~g}^{-1}$ for the original $\mathrm{TiOF}_{2}$ (a) and hydrogenated $\mathrm{TiOF}_{2}$ (b). The cycle performance (c) and Coulombic efficiency curves (d) of the original $\mathrm{TiOF}_{2}$ and hydrogenated $\mathrm{TiOF}_{2}$ at the first cycle at a current density of $42 \mathrm{~mA} \mathrm{~g}^{-1}$, the second cycle at a current density of $210 \mathrm{~mA} \mathrm{~g}^{-1}$, and then other cycle at a current density of $1053 \mathrm{~mA} \mathrm{~g}^{-1}$ in voltage ranges $1.0-3.0 \mathrm{~V}$.

Fig. 4. Rate performance (a, unit: $\mathrm{mA} \mathrm{g}^{-1}$ ) and comparison of the average charge capacities (b) of $\mathrm{TiOF}_{2}$ and $\mathrm{H}-\mathrm{TiOF}_{2}$ at various current density.

Fig. 5 XPS spectra of $\mathrm{TiOF}_{2}$ and $\mathrm{H}_{-} \mathrm{TiOF}_{2}$ : (A) global survey, (B) Ti 2p core-level, (C) O 1s core-level, and (D) F 1s core-level.

Fig. 6 (A) FTIR spectra, (B) I-V curves, (C) M-S plots, and (D) the ECSAs of $\mathrm{TiOF}_{2}$ and $\mathrm{H}-\mathrm{TiOF}_{2}$. 

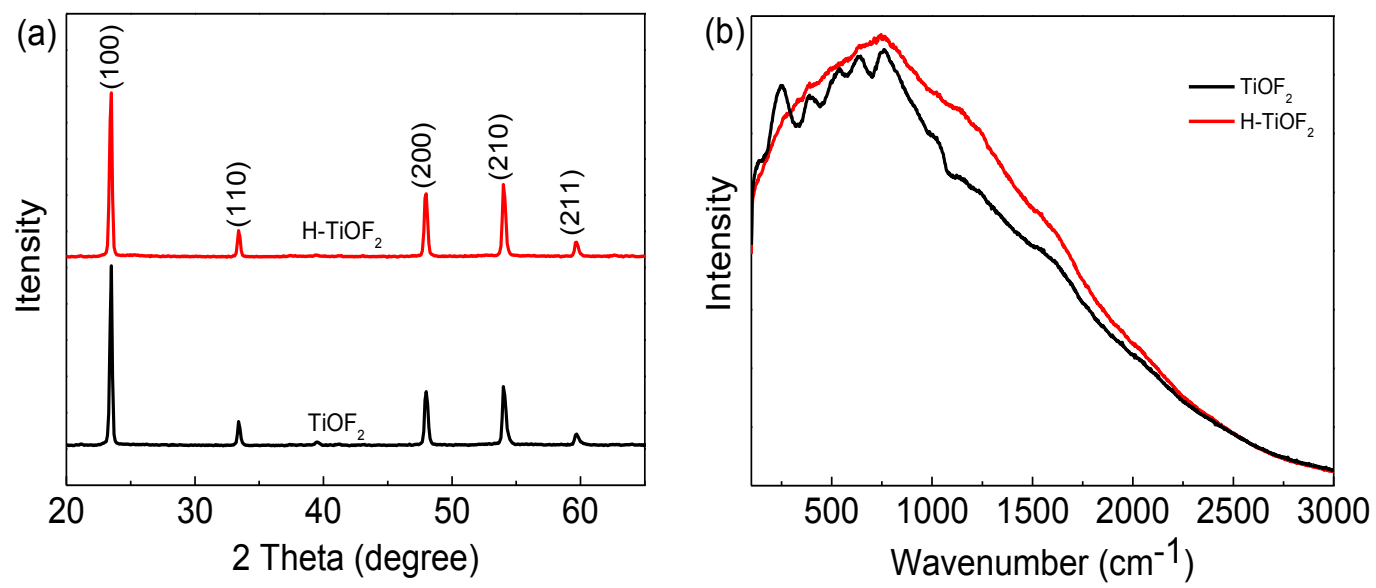

Fig. 1. XRD patterns (a) and Raman spectra of as-synthesized $\mathrm{TiOF}_{2}$ and $\mathrm{H}-\mathrm{TiOF}_{2}$ 

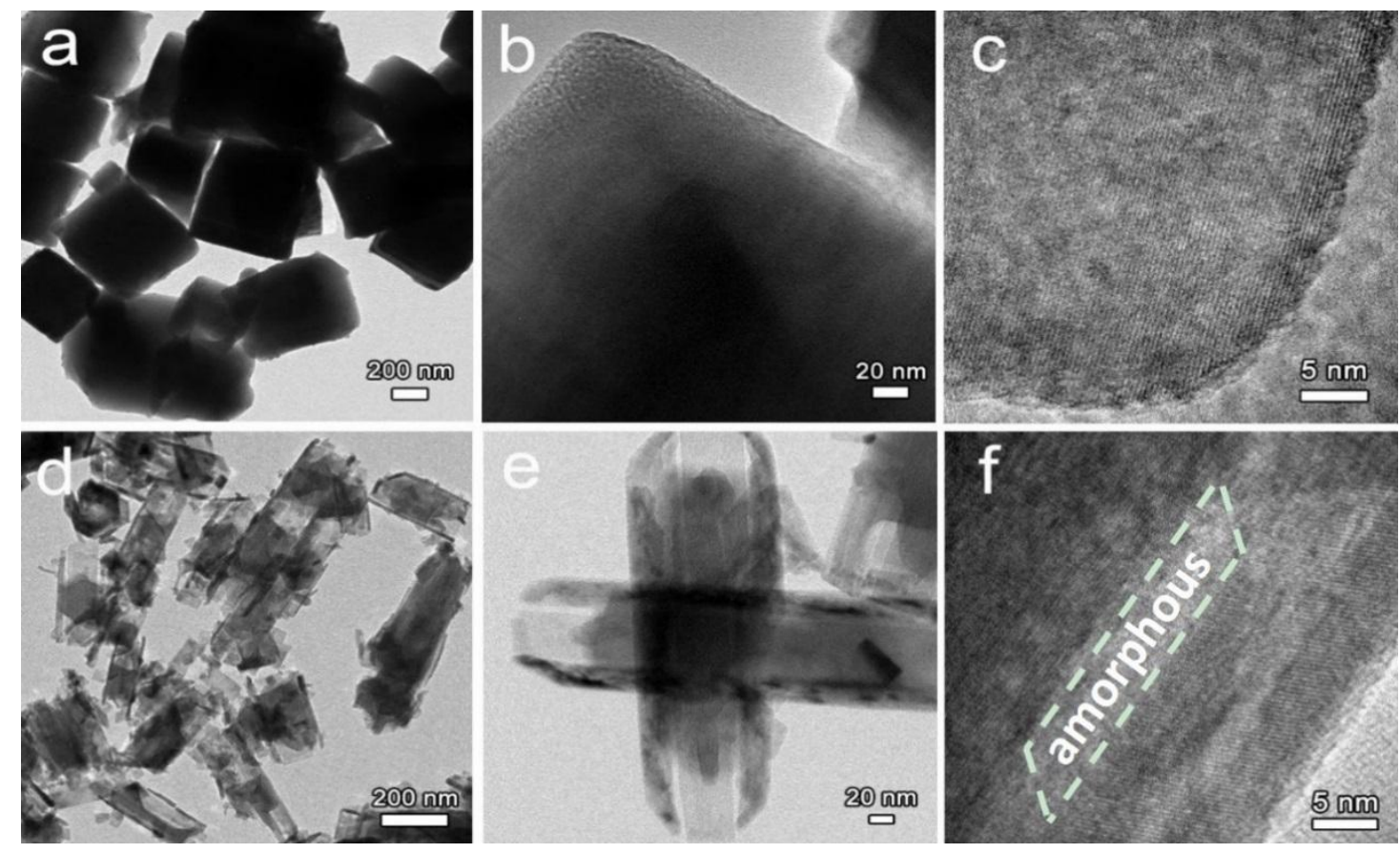

Fig. 2. TEM and HRTEM images of the original $\mathrm{TiOF}_{2}(\mathrm{a}-\mathrm{c})$ and hydrogenated $\mathrm{TiOF}_{2}$ (d-f) 

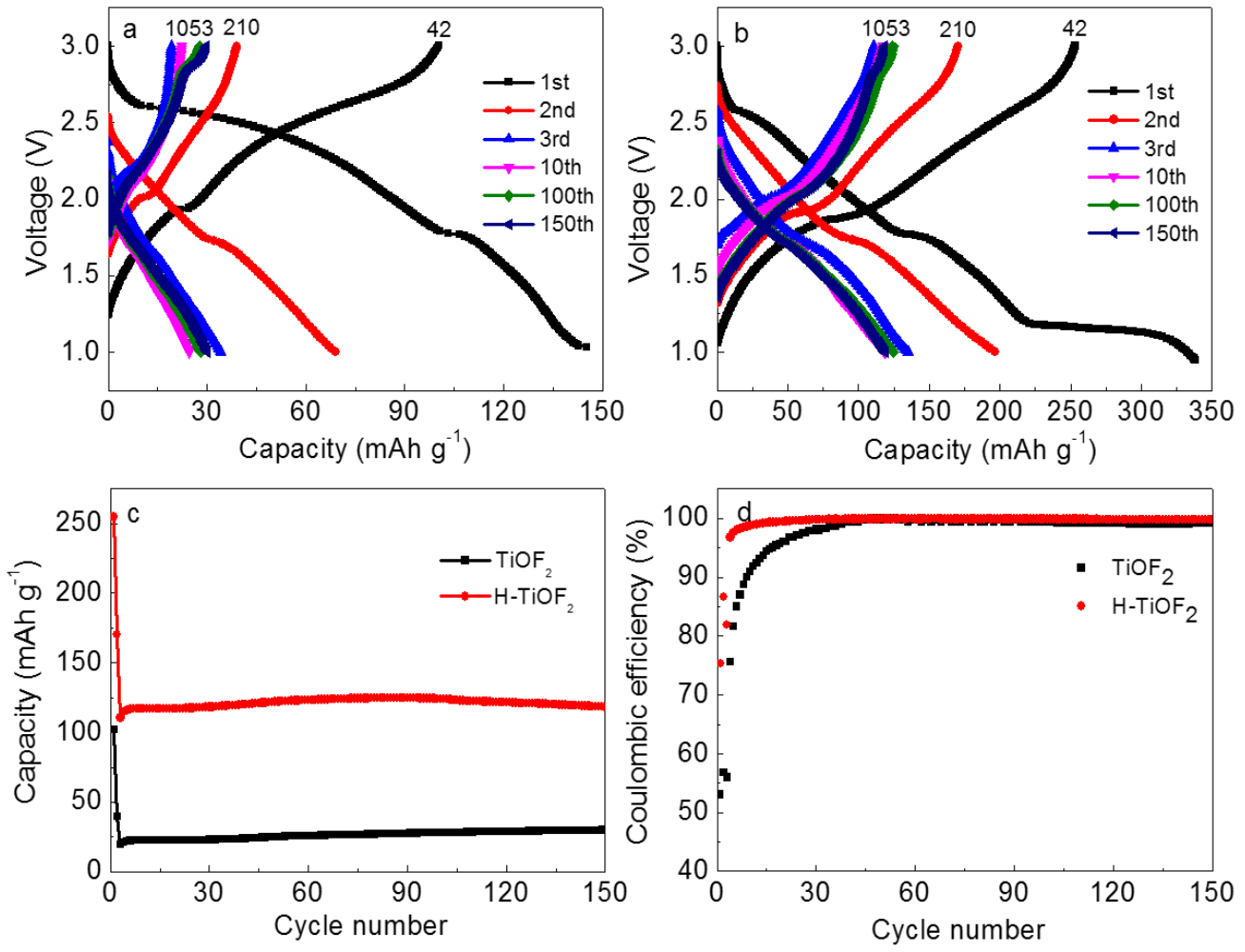

Fig. 3. Galvanostatic charge/discharge profiles at the first cycle at a current density of $42 \mathrm{~mA} \mathrm{~g}^{-1}$, the second cycle at a current density of $210 \mathrm{~mA} \mathrm{~g}^{-1}$, and then other cycles at a current density of $1053 \mathrm{~mA} \mathrm{~g}^{-1}$ for the original $\mathrm{TiOF}_{2}$ (a) and hydrogenated $\mathrm{TiOF}_{2}$ (b). The cycle performance (c) and Coulombic efficiency curves (d) of the original $\mathrm{TiOF}_{2}$ and hydrogenated $\mathrm{TiOF}_{2}$ at the first cycle at a current density of $42 \mathrm{~mA} \mathrm{~g}^{-1}$, the second cycle at a current density of $210 \mathrm{~mA} \mathrm{~g}^{-1}$, and then other cycle at a current density of $1053 \mathrm{~mA} \mathrm{~g}^{-1}$ in voltage ranges $1.0-3.0 \mathrm{~V}$. 

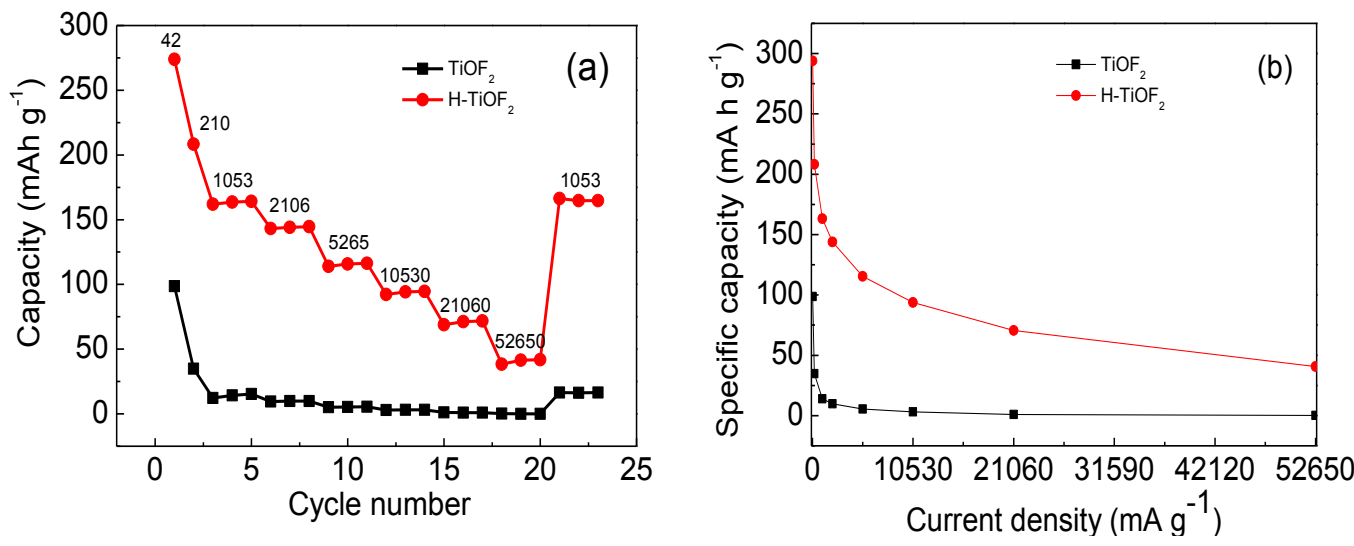

Fig. 4 Rate performance (a, unit: $\mathrm{mA} \mathrm{g}^{-1}$ ) and comparison of the average charge capacities (b) of $\mathrm{TiOF}_{2}$ and $\mathrm{H}-\mathrm{TiOF}_{2}$ at various current density. 

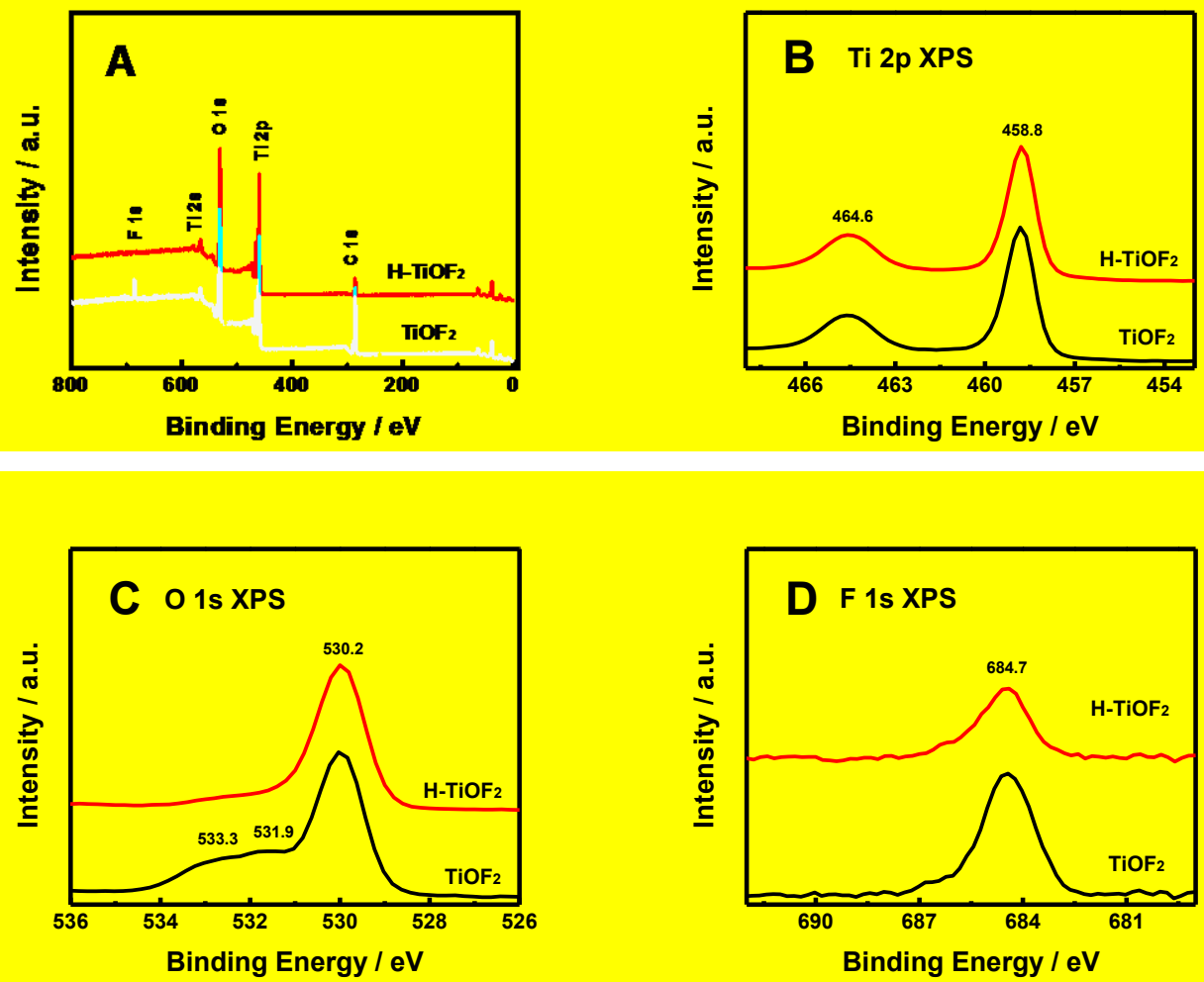

Fig. 5 XPS spectra of $\mathrm{TiOF}_{2}$ and $\mathrm{H}-\mathrm{TiOF}_{2}$ : (A) global survey, (B) Ti 2p core-level, (C) O 1s core-level, and (D) F 1s core-level. 

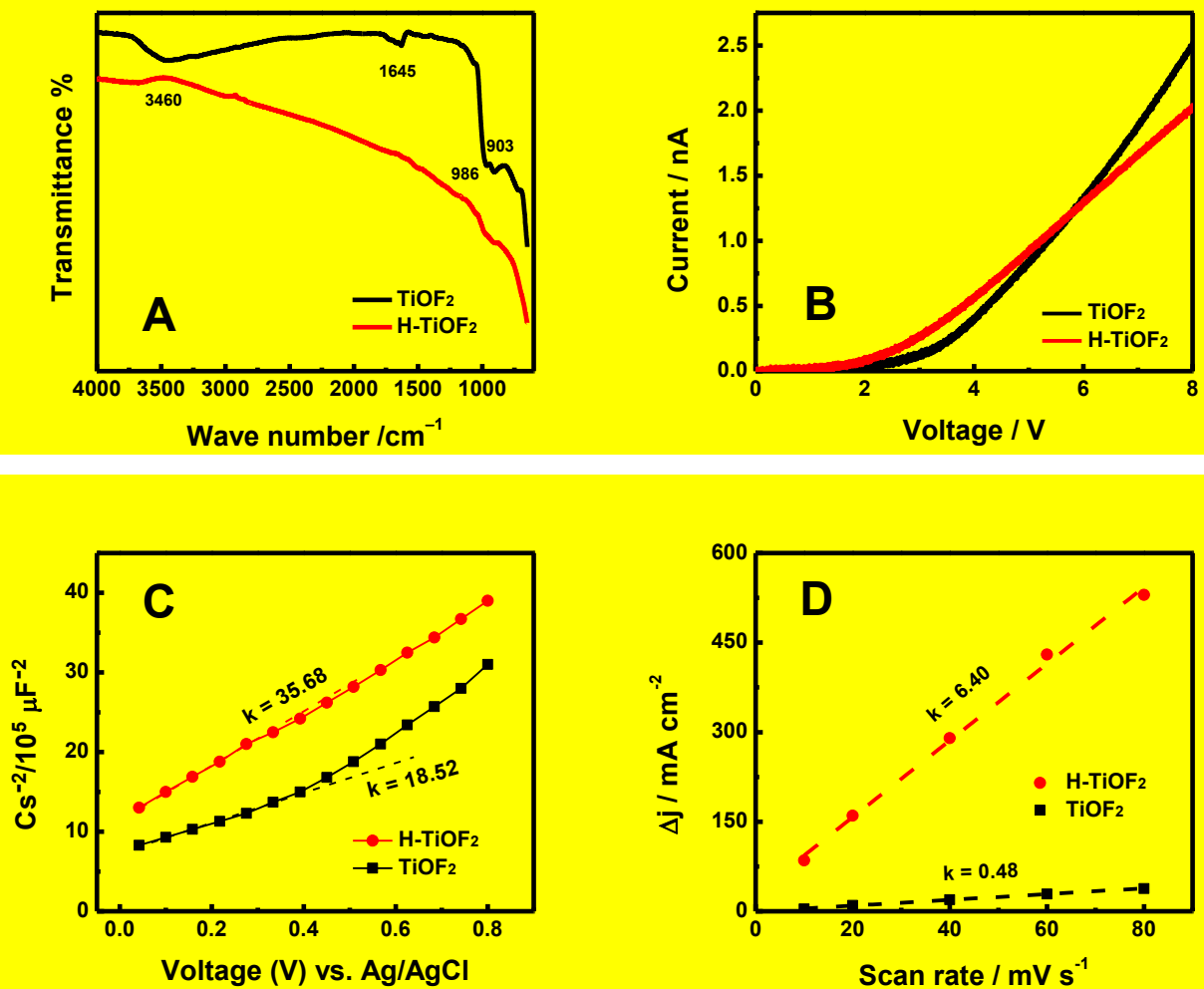

Fig. 6 (A) FTIR spectra, (B) I-V curves, (C) M-S plots, and (D) the ECSAs of $\mathrm{TiOF}_{2}$ and $\mathrm{H}-\mathrm{TiOF}_{2}$. 